\title{
Diagnostic Imaging of Retinoblastomas: About 54 Cases
}

\author{
M. Badraoui*, D. Basraoui, H. Jalal
}

Department of Pediatric Radiology, Mother and Child Hospital, Marrakech, Morocco

DOI: $10.36347 /$ sjmcr.2020.v08i02.039

| Received: 26.01.2020 | Accepted: 02.02.2020 | Published: 27.02.2020

*Corresponding author: Marouane Badraoui

\section{Abstract}

\section{Original Research Article}

Retinoblastoma is the frequent ocular malignant tumor of the genes in children. It mainly affects infants and young children with a very high cure rate of around $95 \%$, provided that an early radiological diagnosis is made with a accurate extension report. Show the contribution of imaging in the diagnosis and management of retinoblastomas. Retrospective study between January 2012 and October 2019, 54 cases of retinoblastoma in children under 15 years. All our patients received an ultrasound and an orbital scan. The mean age was 3 years [ 2 mos- 15 years] with a male predominance. Leukocoria followed by exophthalmia are the most common telling signs. In $84 \%$ of the cases, it is unilateral (rarely bilateral except in family forms). Imaging in retinoblastoma plays a very important role in positive diagnosis when the fundus of the eye is not characteristic or impossible (intra-vitreous haemorrhage), and in the pretherapeutic extension report to adapt the therapeutic management and improve the prognosis in the long term.

Keywords: Retinoblastoma, imaging, children.

Copyright @ 2020: This is an open-access article distributed under the terms of the Creative Commons Attribution license which permits unrestricted use, distribution, and reproduction in any medium for non-commercial use (NonCommercial, or CC-BY-NC) provided the original author and source are credited.

\section{INTRODUCTION}

Retinoblastoma is the frequent ocular malignant tumor of the genes in children. It mainly affects infants and young children with a very high cure rate of around $95 \%$, provided that an early radiological diagnosis is made with a accurate extension report.

\section{Materials ANd Methods}

Retrospective study between January 2012 and October 2019, 54 cases of retinoblastoma in children under 15 years. All our patients received an ultrasound and an orbital scan.

\section{RESULTS}

The average age of our patients was 3 years ( 2 months-15 years) with a male predominance (sex ratio
1.4). Leukocoria followed by exophthalmia were the most frequent telltale signs. It was unilateral in $84 \%$ of the cases.

Ultrasound showed a mass more echoic than vitreous, vascularized with color Doppler, with very hyperechoic areas with or without posterior shadow cone (micro or macro calcifications) in $90 \%$ of cases (Figure-1).

Orbital CT showed extra-scleral orbital extension in $5 \%$ of cases (Figure-2), retro-laminar invasion particularly of the optic nerve in $5 \%$ of cases (Figure-2), calcifications in 93\% of cases (Figure-3) and intense contrast enhancement with retinal detachment in $5 \%$ of cases.
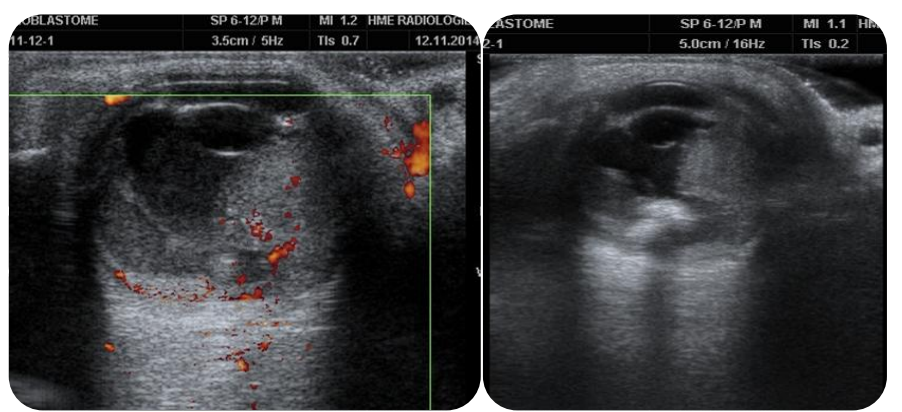

Fig-1: Ocular ultrasound: solid heterogeneous echogenic mass vascularized with color Doppler and containing calcifications with posterior shadow cone 


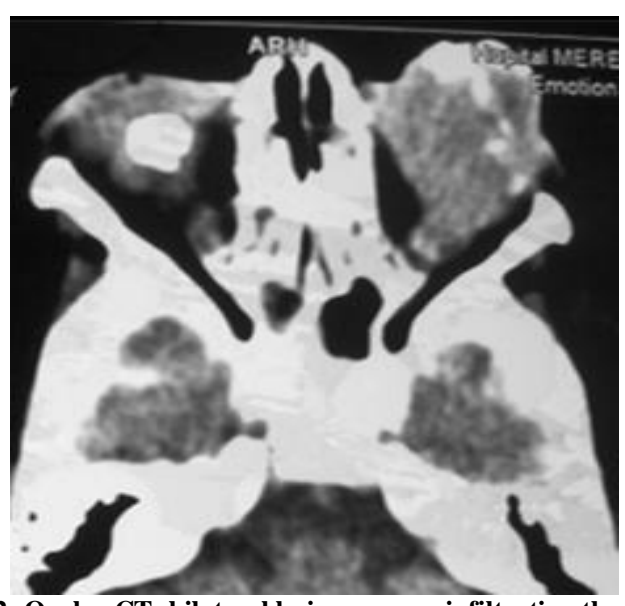

Fig-2: Ocular CT: bilateral lesion process infiltrating the obtic nerves, the oculomotor muscles, the intra and extra colic grisse with macrocalcifications

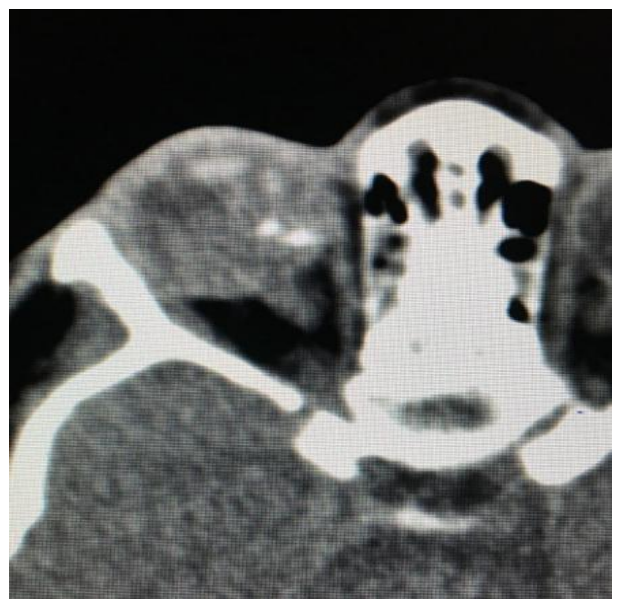

Fig-3: Ocular CT: intraocular lesion process calcification seat without extra-scleral invasion or optic nerve

\section{DisCUSSION}

Retinoblastoma is a neuroectodermal tumor developed from the retina [1], it is malignant of genetic origin by constitutional mutation of the gene $\mathrm{Rb} 1$ (13q14) this mutation predisposes to other types of cancers including sarcomas [1], its incidence is in the order of $1 / 15000$ to $1 / 20000$ births [1], occurred before the age of 3 years in $98 \%$. Its seat is unilateral in $60 \%$ and bilateral in the family forms [1]. The diagnosis of retinoblastoma is clinically suspected by leukocoria and / or exophthalmos [2], is confirmed by a fundus examination which objectifies a whitish tumor with angiomatous dilatation of the retinal vessels [2], there are three forms of retinoblastoma the form endophytic interesting the inner layers of the retina, an exophytic layer interesting the outer layers of the retina and a diffuse infiltrative form that is misleading is often affects older children.

When the fundus examination is not characteristic or impossible, imaging plays a role in the confirmation of diagnosis, evaluation of the size of the tumor process, search for calcifications, assessment of local extension and the search for metastases to the central nervous system. Ultrasonography is the first examination to be performed after the fundus examination ideally performed under general anesthesia and objective a solid heterogeneous echogenic mass vascularized with color Doppler and having calcifications [2]. Orbital CT is essential to study the extra-scleral orbital extension, the retro-laminar invasion in particular of the optic nerve, the presence of calcifications which are present in $93 \%$ of the cases grouped in clusters in the vitreous and the intense contrast enhancement with or without detachment of the retina [3]. Orbital CT can also be used to search for other intra-cranial abnormalities such as intracranial tumor extension, midline tumors and malformative abnormalities [3].

\section{CONCLUSiON}

Imaging plays a key role in the positive diagnosis of retinoblastoma when the fundus is not characteristic or impossible (intra-vitreous haemorrhage), and in the pre-therapeutic extension report to adapt the therapeutic management and improve the prognosis in the long term.

\section{REFERENCES}

1. Aerts I, Lumbroso-Le Rouic L, Gauthier-Villars M, Brisse H, Doz F, Desjardins L. Retinoblastoma. Orphanet journal of rare diseases. 2006 Dec 1;1(1):31.

2. Kaste SC, Jenkins III JJ, Pratt CB, Langston JW, Haik BG. Retinoblastoma: sonographic findings with pathologic correlation in pediatric patients. American Journal of Roentgenology. 2000 Aug;175(2):495-501.

3. Brisse HJ, Guesmi M, Aerts I, Sastre-Garau X, Savignoni A, Lumbroso-Le Rouic L, Desjardins L, Doz F, Asselain B, Bours D, Neuenschwander S. Relevance of CT and MRI in retinoblastoma for the diagnosis of postlaminar invasion with normalsize optic nerve: a retrospective study of 150 patients with histological comparison. Pediatric radiology. 2007 Jul 1;37(7):649-56. 